\title{
BMJ Global Health Europe should lead in coordinated procurement of quality-assured medicines for programmes in low- income and middle-income countries
}

\author{
Christophe Perrin, ${ }^{1}$ Sandrine Cloez, ${ }^{1}$ Catherine Dujardin, ${ }^{2}$ Raffaella Ravinetto (D ${ }^{3}$
}

To cite: Perrin C, Cloez S, Dujardin C, et al. Europe should lead in coordinated procurement of quality-assured medicines for programmes in low-income and middle-income countries. BMJ Global Health 2020:5:e003283. doi:10.1136/ bmjgh-2020-003283

Received 29 June 2020 Accepted 4 July 2020
Check for updates

C Author(s) (or their employer(s)) 2020. Re-use permitted under CC BY-NC. No commercial re-use. See rights and permissions. Published by BMJ.

${ }^{1}$ Independent Expert, Paris, France

${ }^{2}$ Belgian Directorate-General for Development Cooperation \& Humanitarian Aid (DGD) Brussels, Belgium

${ }^{3}$ Public Health Department, Institute of Tropical Medicine, Antwerp, Belgium

Correspondence to Raffaella Ravinetto; rravinetto@itg.be
A secured supply of quality-assured medicines and other medical products is an essential prerequisite for universal health coverage. Unfortunately, on average one in 10 medicines do not meet acceptable quality standards in low-income and middle-income countries (LMICs). ${ }^{12}$ The high prevalence of poor-quality medicines in LMICs greatly depends on the globalisation of pharmaceutical production and distribution, combined with the weakness of many national medicines regulatory authorities (NMRAs). ${ }^{34}$ The use of non-quality-assured medicines, often undetected, causes poor case management and unfavourable medical outcomes in individual patients, while at population level, it is translated in poor control of communicable diseases, emergence of resistance to medicines and loss of trust in health systems. ${ }^{24-6}$ Risks are magnified by the COVID-19 pandemic, which triggered disruption of supply chains, stockouts, substandard production, falsification of repurposed medicines and irrational use of medicines. $^{78}$

European taxpayers' money is used to fund medical programmes in LMICs in the context of humanitarian aid and development. Medicines for these programmes are purchased either at international suppliers specialised in the humanitarian sector, or locally in the countries or regions of intervention. These purchases are not exempted from the quality risks that exist in the local and international market. Hence, adequate pharmaceutical procurement and quality assurance (QA) policies are needed for three reasons. First, to mitigate the risk of purchasing products of poor quality. Second, to assure the same quality standards that would be required for medicines marketed in the donor country. ${ }^{9}$ Third, these policies are needed to address fundamental moral

\section{Summary box}

Thoughtful procurement policies in humanitarian and development medical programmes can mitigate the risk of purchasing poor-quality medicines, allowing to address fundamental moral obligation to equity, transparency and accountability.

- European donors are aware of the quality problems in the global pharmaceutical market, and some are already translating awareness into explicit procurement and quality assurance policies. However, a joint position and coordinated action is lacking.

- European donors should share existing knowledge and tools, seek the input of recipient countries, and develop a joint position on how the donor community can help to ensure access to affordable and qualityassured health products-also during public health emergencies such as the COVID-19 pandemic.

- Applying stringent and harmonised quality assurance requirements, European donors and their implementing organisations can help shaping the global pharmaceutical market towards affordable, quality assured products.

obligations in terms of equity, transparency and accountability. ${ }^{10}$

Various European donors play distinct and complementary roles here: the European Commission (EC), the national Ministries of Foreign Affairs and the national development cooperation agencies with their aid implementers. The role of donor agencies is particularly crucial. If a donor does not prioritise QA requirements in pharmaceutical procurement policies, and does not foresee a dedicated budget line to secure quality, its aid implementers might choose supply channels that are not fully reliable, or they might purchase medicines that are not subject to stringent regulation even if they are authorised in the recipient country. ${ }^{911}$ 


\section{AWARENESS VERSUS POLICIES}

A stakeholder survey carried out at the end of 2019 by the Institute of Tropical Medicine in Antwerp, Belgium, shed some preliminary light on the procurement policies adopted by a sample of 26 European donors and implementing actors of the national cooperation programmes. ${ }^{12}$

Most European donors in the sample directly or indirectly fund the purchase of medicines for development or humanitarian assistance programmes within their Official Development Assistance (ODA) (73\%). They are aware of the high prevalence of poor-quality medicines in these contexts $(67 \%)$ and they acknowledge the need for stringent QA requirements in procurement policies. ${ }^{12}$ But awareness is not always translated into formal QA policies and guidelines. Only a minority (20\%) have developed or implemented internal policy briefs, or procurement policies with clear specifications for pharmaceutical QA. There is a lack of structured mechanisms for the monitoring and evaluation (M\&E) of pharmaceutical quality in procurement, and no respondents mentioned any provisions for risk management plans.

Nonetheless, there are also some positive examples of targeted QA policies. In particular, four European donors set the tone. The Directorate-General (DG) European Civil Protection and Humanitarian Aid Operations (ECHO) of the EC specifically requires that their aid implementers use positive lists of approved procurement entities. To this aim, DG ECHO has published since 2003 a list of Humanitarian Procurement centres, assessed according to their quality systems, indicating where to procure medical supplies in priority. ${ }^{13}$ Among EU member states, Belgium explicitly requires since 2017 that aid implementers ensure the quality of medicines procured for medical programmes in LMICs and avoid double-quality standards between the donor and the recipient country. ${ }^{9}$ Sweden publicly acknowledges its effort to incorporate guiding principles on QA into its contractual requirements with aid implementing partners ${ }^{14}$; and in June 2019, the UK implemented an internal QA guidance for procurement and supply of medicines inspiring broader guiding principles for donors. ${ }^{14}$

There are various reasons for the apparent delay of other European donors. First, securing safe supply chains meets a variety of hurdles, such as the need of complex contractual arrangements with suppliers, as well as the need of adequate tools for M\&E, the institutional lack of specific QA expertise at donors and aid implementers' level and the fear that products that have been rigorously assessed for quality would be more expensive. Second, some donors may consider that assuring the quality of medicines remains the sole responsibility of aid implementers and/or recipient countries. Third, $20 \%$ of donors in our sample explicitly rely on the QA policies of the international actors they support, such as United Nations (UN) agencies, the Global Fund to fight AIDS, Tuberculosis and Malaria (GFATM) and the Gavi Alliance-even if they did not mention any specific policy dialogue with these organisations on pharmaceutical quality in procurement.

It is also encouraging that in absence of explicit formal QA policies, awareness is translated into a variety of other initiatives that aim to support recipient countries in pharmaceutical $\mathrm{QA}$, and to mitigate the risk of purchasing poor-quality medicines (table 1 ). These initiatives are either direct, for example, QA trainings for staff and implementers, and/or capacity building projects for national procurement units or NMRAs; or indirect, through the support to international mechanisms such as the WHO Prequalification Programme ${ }^{15}$ and the WHO Global Surveillance and Monitoring System for Substandard and Falsified products. ${ }^{1}$ Many European donors also have internal mechanisms to report quality incidents occurring with medicines purchased with their funds; but it is not clear to what extent findings are shared with peers, and used to adapt and improve existing procurement policies or to orient the policy setting agenda.

\section{POLICIES VERSUS ACCOUNTABILITY AND RISK MANAGEMENT}

In an ideal world, each country would count on a stringent NMRA, able to ensure the quality of medicines manufactured, distributed or imported into their territory. Bilateral and multilateral donors can contribute to reinforcing under-resourced NMRAs, through targeted capacity building programmes, in the frame of health systems strengthening. However, as long as this longterm aim is not achieved ${ }^{16}$ and many recipient LMICs cannot secure QA in their own procurement, donors can support them by setting explicit and stringent QA policies for procurement of medicines in the programmes they fund. By doing so, they would be accountable about the optimal and ethical use of ODA resources, both to recipient countries, and to tax payers and parliaments in their own countries.

Pharmaceutical QA should become an integral part of donors' risk management plans and policies. Adequate QA policies can be direct or indirect. When funds are directly disbursed by a donor, the donor would require its implementers to purchase medicines according to its own QA policy. When funds are indirectly disbursed through channels such as multilateral or bilateral cooperation, humanitarian programmes, non-governmental organisations, investment funds or development banks, the donors would make use of policy dialogue (eg, via their official representation at Board meetings) to monitor whether adequate QA standards are applied and evaluated. Monitoring and evaluating a (direct or indirect) QA policy requires donors and aid implementers having easy, ongoing access to disaggregated financial data within ODA budgets. This allows them to trace funds spent on pharmaceutical purchases and/or QA capacity building and provides access to up-to-date indicators of availability and quality of essential medicines in medical programmes. 
Table 1 Initiatives to mitigate the risk of purchasing poor-quality medicines

\begin{tabular}{|c|c|}
\hline Risk mitigating strategies & $\%$ of respondents \\
\hline \multicolumn{2}{|l|}{ Procurement policies in place } \\
\hline $\begin{array}{l}\text { Recognising the pharmaceutical regulatory standards set by the WHO and/or Stringent } \\
\text { Regulatory Authorities }\end{array}$ & 33 \\
\hline $\begin{array}{l}\text { Using positive lists of procurement agencies which have been assessed for compliance to } \\
\text { WHO quality standards }\end{array}$ & 17 \\
\hline Implementing some level of checks on medicine purchases done by implementing partners & 17 \\
\hline Providing QA training to staff at donor and/or implementing partners & $\begin{array}{l}\text { Implemented } 42 \\
\text { Planned } 17\end{array}$ \\
\hline Monitoring use of donor funding channelled through UN agencies, GFATM & 25 \\
\hline \multicolumn{2}{|l|}{ Direct support to recipient countries } \\
\hline Funding capacity building for pharmaceutical procurement/supply & 58 \\
\hline Providing technical support from NMRA in the donor country, to NMRAs in LMICs & 42 \\
\hline Providing QA training to Procurement Units & 17 \\
\hline Funding national QC laboratory & 8 \\
\hline \multicolumn{2}{|l|}{ Indirect support to recipient countries } \\
\hline Supporting the WHO Prequalification Programme & 17 \\
\hline Supporting regional regulatory harmonisation initiative(s) & 25 \\
\hline Supporting the WHO's Global Surveillance and Monitoring System for SF products & 8 \\
\hline Funding research and/or platforms providing technical support for implementing partners & 8 \\
\hline
\end{tabular}

GFATM, Global Fund to fight AIDS, Tuberculosis and Malaria; LMICs, low-income and middle-income countries; NMRAs, national medicines regulatory authorities; QA, quality assurance; SF, substandard and falsified.

Presently, the QA policies and the mechanisms for accountability and risk management still vary across European development and humanitarian aid programmes, and only a minority of European donors have explicit QA policies in place. Harmonisation of such policies across donors would allow setting adequate standards across aid programmes, and to achieve a better protection of individual and public health in recipient countries.

\section{TOWARD EUROPEAN HARMONISATION AND GUIDANCE?}

Efforts to build a common approach across European donors should be encouraged, but are still in their infancy. The existing models ${ }^{91314}$ and best practices could serve as a basis for other European donors to develop internal policies adapted to their own cooperation strategies, in the frame of a process of European harmonisation. Importantly, the input of aid recipient countries should be requested and taken into due account, so as to codesign policies and procedures which respond to existing needs.

But European donors could be more ambitious. In line with the resolution developed for the seventy-third World Health Assembly on the COVID-19 pandemic, ${ }^{17}$ they could develop a joint guiding position to affirm how the European donor community should and can collectively ensure equitable access to and availability of qualityassured health products, including medicines. Compared with other approaches that focus on developing market opportunities, or that fail to integrate concerns about pharmaceutical quality, European donors can collectively take leadership in promoting the universal right to safe, quality-assured medicines internationally, in partnership with their counterparts from LMICs.

European donors could also consider proactively sharing the available information on quality of medicines among themselves, and with recipient countries. They could consider adopting mutual recognition of policies and tools that help securing pharmaceutical quality for all. For instance, European donors could agree on positive lists of procurement entities, at international level and in aid recipient countries; ${ }^{13}$ they could share reports on qualified manufacturers at international level and in aid recipient countries; and they could share price lists for priority essential medicines in contexts where several European donors intervene.

These measures would be particularly helpful for emergency preparedness. During disasters and outbreaks of infectious diseases there are increased, urgent pharmaceutical needs. In a crisis, purchases need to be done rapidly, with no time for in-depth prequalification of products and suppliers. The ongoing COVID-19 pandemics shows that not only LMICs, but also high-income countries are confronted with quality problems under such circumstances, for example, for personal protective equipment and diagnostic tests. ${ }^{18}{ }^{19}$ Under these complex circumstances, the resources and know-how of European donors and their aid implementers could contribute to securing a supply of quality-assured health products, by 
addressing the underlying vulnerabilities in regulations, markets and supply chains. A comprehensive assessment of European initiatives to support recipient countries could help designing and refining shared best practices. This could be the basis for a reliable procurement system for health products, in line with the joint programming scheme where various European donors and their implementing partners aim at maximal complementarity when addressing health needs in the same recipient countries. ${ }^{20}$

There may be fears that quality-assured products are costly, and that additional costs would not be compatible with the attainment of universal health coverage. However, the prices of health products do not depend on manufacturing and QA costs only, but also on manufacturing volumes and market opportunities. If all European donors and their aid implementers would apply stringent and harmonised QA requirements in their procurement policies, they could contribute to shaping the market of LMICs towards affordable and quality assured products. ${ }^{21}$ This would require awareness and political will at (higher) institutional level, enhanced coordination across European donors, and consideration for the hidden-yet high — cost of inaction for individual and public health.

Twitter Raffaella Ravinetto @RRavinetto

Acknowledgements We are grateful to DG DEVCO and DG ECHO of the European Commission; the Ministries of Foreign Affairs in Belgium, Denmark, France, Germany, Italy, Ireland, Luxembourg, Netherlands, Spain, Sweden and Switzerland; and the aid implementers of the national cooperation programmes in Belgium, France, Germany, Italy, Ireland, Netherlands, Norway, Spain, Sweden, Switzerland and the United Kingdom. We thank Roeland Scholtalbers for re-reading and editing the manuscript.

Contributors This Analysis is based on the findings of a survey conducted in collaboration between the Belgian Directorate-General for Development (DGD) and the Institute of Tropical Medicine (ITM), and funded by the DGD. CP and SC, two pharmacists with broad expertise in pharmaceutical quality assurance, supply chains and access to essential medicines, are the independent experts who conducted and reported the survey. $\mathrm{CD}$, a pharmacist with broad experience in public health policies, policy support for development and humanitarian programmes, and health systems strengthening, is a full-time civil servant at the Belgian DGD; she requested the survey, and was also a respondent to it. RR, a pharmacist, senior researcher and policy advisor at the ITM, was involved in the design, conduct and supervision of the survey. This Commentary was drafted by RR, based on the report written by CP and SC. All Authors contributed to finalising it in the current version. RR is the guarantor of this Commentary and the corresponding author.

Funding The survey which inspired this Commentary was conducted by CP and $\mathrm{SC}$, and funded by the Belgian DGD, through the DGD Framework Agreement 4, 2017-2021 with the Institute of Tropical Medicine, Antwerp.

Competing interests $C D$ is a full-time civil servant of the Belgian DGD, which funded the survey; she was also one of the respondents in this stakeholder survey. RR is a senior researcher at the Institute of Tropical Medicine (ITM) Antwerp, and her position is funded by the Belgian DGD, through the DGD Framework Agreement 4, 2017-2021 with the ITM.

Patient and public involvement Patients and/or the public were not involved in the design, or conduct, or reporting or dissemination plans of this research.

Patient consent for publication Not required.

Provenance and peer review Not commissioned; internally peer reviewed.

Data availability statement All data relevant to the study are included in the article or uploaded as supplementary information.

Open access This is an open access article distributed in accordance with the Creative Commons Attribution Non Commercial (CC BY-NC 4.0) license, which permits others to distribute, remix, adapt, build upon this work non-commercially, and license their derivative works on different terms, provided the original work is properly cited, appropriate credit is given, any changes made indicated, and the use is non-commercial. See: http://creativecommons.org/licenses/by-nc/4.0/.

\section{ORCID iD}

Raffaella Ravinetto http://orcid.org/0000-0001-7765-2443

\section{REFERENCES}

1 World Health Organization. Global surveillance and monitoring system for substandard and falsified medical products. Geneva: World Health Organization, 2017.

2 World Health Organization. A study on the public health and socioeconomic impact of substandard and falsified products: Executive summary. Geneva: World Health Organization, 2017.

3 World Health Organization. Essential medicines and health products. substandard and falsified (SF) medical products. definitions of substandard and falsified (SF) medical products. Geneva: World Health Organization, 2017. https://www.who.int/medicines/ regulation/ssffc/A70_23-en1.pdf?ua=1

4 Newton PN, Bond KC, et al, Oxford Statement signatories. Global access to quality-assured medical products: the Oxford statement and call to action. Lancet Glob Health 2019;7:e1609-11.

5 Newton PN, Caillet C, Guerin PJ. A link between poor quality antimalarials and malaria drug resistance? Expert Rev Anti Infect Ther 2016;14:531-3.

6 Nwokike J, Clark A, Nguyen PP, et al. Medicines quality assurance to fight antimicrobial resistance. Bull World Health Organ 2018;96:135-7.

7 World Health Organization. Information exchange system alert No.3/2020. RPQ/REG/ISF/Alert 3.2020. Falsified medical products, including in vitro diagnostics, that claim to prevent, detect, treat or cure COVID-19, 2020.

8 Newton PN, Bond KC, 53 signatories from 20 countries. COVID-19 and risks to the supply and quality of tests, drugs, and vaccines. Lancet Glob Health 2020;8:e754-e755.

9 Ravinetto R, Roosen T, Dujardin C. The Belgian commitment to pharmaceutical quality: a model policy to improve quality assurance of medicines available through humanitarian and development programs. J Pharm Policy Pract 2018;11:1.

10 Organisation for Economic Co-operation and Development (OECD). Paris Declaration on aid effectiveness. Paris, France: OECD Publishing, 2020.

11 Nebot Giralt A, Ronse M, Ravinetto R. A survey of nongovernmental organizations on their use of WHO's prequalification program. Bulletin of WHO 2020, 2020

12 Perrin C, Cloez S, Ravinetto R. Analysis of the quality assurance and pharmaceutical procurement policies of a sample of European donors, 2020. Available: https://www.itg.be/Files/docs/Report analysis\%20QA\%20pharmaceutical\%20procurement\%20policies EU\%20donors_FV.pdf [Accessed 28 May 2020].

13 DG European Civil Protection and Humanitarian Aid Operations (ECHO). Annex III: principles and procedures applicable to procurement contracts - 01/01/2014. Available: https://ec.europa. eu/echo/files/partners/humanitarian_aid/fpa/2014/FPA_Principles_ Procedures_en.pdf [Accessed 25 May 2020].

14 Assuring medicines quality in medicines procurement. Available: https://www.itg.be/Files/docs/Assuring_Medicine_Quality_WHA_RT_ 7_2_519.pdf [Accessed 25 May 2020].

15 't Hoen EFM, Hogerzeil HV, Quick JD, et al. A quiet revolution in global public health: the world Health organization's prequalification of medicines programme. J Public Health Policy 2014;35:137-61.

16 WHO global benchmarking tool (GBT) for evaluation of national regulatory system of medical products. National regulatory system (RS): indicators and fact sheets. revision VI version 1. Geneva: World Health Organization, 2018. https://www.who.int/medicines/areas/ regulation/01_GBT_RS_RevVI.pdf?ua=1

17 SEVENTY-THIRD World health assembly A73/CONF./1 Rev.1 agenda item 318 may 2020. COVID-19 response. draft resolution proposed by Albania, Australia, Azerbaijan, Bahrain, Bangladesh, Belarus, Bhutan, Bolivia (Plurinational state of), Brazil, Canada, Chile, China, Colombia, Cook Islands, Costa Rica, Djibouti, Dominican Republic, Ecuador, El Salvador, Fiji, Georgia, Guatemala, Guyana, Honduras, Iceland, India, Indonesia, Iraq, Jamaica, Japan, Jordan, Kiribati, Maldives, Marshall Islands, Mexico, Micronesia (Federated states of), Monaco, Montenegro, Morocco, Nauru, Nepal, New Zealand, North Macedonia, Norway, Panama, Papua New Guinea, Paraguay, Peru, Philippines, Qatar, Republic of Korea, Republic of Moldova, 
Russian Federation, San Marino, Saudi Arabia, Serbia, Singapore, Sri Lanka, Thailand, the African group and its member states, the European Union and its member states, Tonga, Tunisia, Turkey, Ukraine, United Kingdom of great britain and Northern Ireland and Uruguay. Available: https://apps.who.int/gb/ebwha/pdf_files/ WHA73/A73_CONF1Rev1-en.pdf [Accessed 25 May 2020].

18 European Safety Federation. Covid 19 suspicious certificates for PPE - updated 11/05/2020. Available: https://www.eu-esf.org/covid19/4513-covid-19-suspicious-certificates-for-ppe [Accessed 25 May 2020].

19 Guidance on the use of COVID-19 rapid diagnostic tests. ITM researchers wrote a position paper to guide the use of rapid diagnostic tests to test for COVID-19 infection. 09-04-20. Available: https://www.itg.be/E/Article/guidance-on-the-use-of-covid-19-rapiddiagnostic-tests [Accessed May 2020].

20 Joint programming of development cooperation. Cooperating internationally to programme development aid and, develop a coordinated, strategic response to key global challenges. Available: https://ec.europa.eu/info/aid-development-cooperationfundamental-rights/ensuring-aid-effectiveness/joint-programmingdevelopment-cooperation_fr [Accessed 25 May 2020].

21 Ravinetto R, Dujardin C. Universal health coverage: drug quality and affordability can go together. BMJ 2019;367:16004. 